\title{
Arbuscular mycorrhiza and plant chromium tolerance
}

\author{
Songlin $\mathrm{Wu}^{1,2}$, Xin Zhang ${ }^{1}$, Longbin Huang ${ }^{2}$, Baodong Chen ${ }^{1,3, *}$ \\ 1 State Key Laboratory of Urban and Regional Ecology, Research Center for Eco-Environmental Sciences, Chinese Academy of Sciences, \\ Beijing 100085, China \\ 2 Environment Centres (CMLR), Sustainable Minerals Institute, The University of Queensland, Brisbane, Queensland 4072, Australia \\ 3 University of Chinese Academy of Sciences, Beijing 100049, China
}

\section{ARTICLE INFO}

\section{Article history:}

Received December 14, 2018

Revised February 15, 2019

Accepted March 18, 2019

\section{Keywords:}

Arbuscular mycorrhizal fungi

Heavy metal

Chromium

Tolerance

Translocation and transformation

Bioremediation

\begin{abstract}
A B S T R A C T
Arbuscular mycorrhizal (AM) fungi are ubiquitous soil fungi that form symbiotic associations with most terrestrial plants. The growth and functions of AM fungi depend on carbohydrates supplied by the plants, in return, the fungi assist the plants to acquire mineral nutrients (e.g., phosphorus) from soil. The AM symbiosis also improves plant survival in various unfavorable environments, such as metal (loid) contaminated soil. It has been well demonstrated that AM symbiosis improved plant adaptation to $\mathrm{Cr}$ contamination, which would have a great potential in phytoremediation and ecological restoration of $\mathrm{Cr}$ contaminated soils. In this paper, we have reviewed the role of $\mathrm{AM}$ fungi in alleviation of $\mathrm{Cr}$ phytotoxicity and associated factors influencing plant $\mathrm{Cr}$ tolerance. AM symbiosis improves plant $\mathrm{Cr}$ tolerance through its direct roles in $\mathrm{Cr}$ stabilization and transformation and indirect roles via AM symbiosis mediated nutrient acquisition and physiological regulation. Future research on physiological and molecular mechanisms underlying $\mathrm{Cr}$ behavior and detoxification in AM symbiosis, as well as potential use of $\mathrm{AM}$ fungi in ecological restoration and agriculture production in $\mathrm{Cr}$ contaminated soils were also proposed.
\end{abstract}

() Higher Education Press 2019

\section{Introduction}

Chromium ( $\mathrm{Cr}$ ) is a common element widely used in electroplating, steel plating, dyeing, tanning, and leather production etc. However, $\mathrm{Cr}$ pollution has recently become a serious environmental problem in many regions and countries, because of excessive discharge of $\mathrm{Cr}$-containing effluents resulting from industrial activities (Zayed et al., 1998). Chromium usually exists in oxidation status as $\mathrm{Cr}$ (III) and $\mathrm{Cr}(\mathrm{VI})$. Chromium(III) is chemically very stable with a low mobility. In contrast, $\mathrm{Cr}(\mathrm{VI})$ is highly mobile, much toxic and

\footnotetext{
* Corresponding author

E-mail address: bdchen@rcees.ac.cn (B.D. Chen)
}

carcinogenic. At low concentrations, $\mathrm{Cr}(\mathrm{III})$ is beneficial to animal and human health as an essential component of glucose tolerance factor (GTF), whereas $\mathrm{Cr}(\mathrm{VI})$ is highly toxic and carcinogenic in human and animals (Losi et al., 1994).

In higher plants, $\mathrm{Cr}$ is not essential to plant growth and function. Exposure to $\mathrm{Cr}$ may cause tissue necrosis and limit chlorophyll production (Sharma et al., 2003; Singh et al., 2013). In particular, $\mathrm{Cr}$ is usually involved in electron transfer and induce production of reactive oxygen species (ROS) (e.g., hydroxyl radicals and superoxide radicals), resulting in oxidative stresses and damages to plant cells and tissues (Appenroth et al., 2000; Shanker and Pathmanabhan, 2004; Kováčik et al., 2013).

In natural environments, plant roots are usually associated with various soil microbes, such as arbuscular mycorrhizal (AM) fungi. AM fungi are ubiquitous soil fungi that form 
symbiotic partnership with most terrestrial plants (Smith and Read, 2008). AM fungi may enhance root's ability and capacity to acquire mineral nutrients (e.g., phosphorus), while in return, they require carbohydrates from the host plants (Smith and Read, 2008; Jiang et al., 2017). In addition, the beneficial effects of AM symbiosis have also been reported on improving plant tolerance to various environmental stresses, such as drought, salinity and soil pollution (Lenoir et al., 2016; Wang, 2017). AM symbiosis was found to improve plant tolerance to heavy metal (e.g., Zn, Cu, Cd, As, $\mathrm{Pb}$ ) contaminations (Leyval et al., 1997; Wu et al., 2013; Ferrol et al., 2016). However, the role of AM fungi in plant $\mathrm{Cr}$ tolerance and the underlying mechanism have not been investigated in detail. Recent studies showed that plant grew better in $\mathrm{Cr}$ contaminated soils when roots were colonized by AM fungi (Davies et al., 2002; Gardezi et al., 2003; Arias et al., 2010a, 2010b; Wu et al., 2014). This review has focused on the role of $\mathrm{AM}$ fungi in plant $\mathrm{Cr}$ tolerance, with the aim to elucidate direct and indirect involvements of AM fungi in $\mathrm{Cr}$ translocation and transformation in the plant-soil continuum.

\section{AM symbiosis development in $\mathrm{Cr}$ contaminated soils}

\subsection{Reports on AM fungi in the natural $\mathrm{Cr}$ contaminated soils}

Many studies showed that AM fungi were present in soils contaminated with heavy metal(loid)s, such as As (Sun et al., 2016), Cu (Chen et al., 2005a), Pb (Long et al., 2010; Zarei et al., 2010), Zn (Zarei et al., 2010) and Cd (González-Chávez et al., 2009). In Cr contaminated soils, AM fungi were found in the rhizosphere of Ricinus communis and Conium maculatum (Gil-Cardeza et al., 2014). Many AM fungal species were found to colonize soils contaminated by tannery waste (containing high concentrations of $\mathrm{Cr}$ ), which belonged to six genera (Acaulospora, Glomus, Gigaspora, Scutellospora, Paraglomus, and Ambispora) (Nakatani et al. 2011). Besides, in some multi-metal (including $\mathrm{Cr}$ ) contaminated soils, $59 \%$ $79 \%$ of the roots were reported to be colonized by AM fungi (Al-Ghamdi and Jais, 2012). These studies have suggested that various AM fungal species are capable of surviving and proliferating in $\mathrm{Cr}$ contaminated soil.

Although AM fungi are found to be present in $\mathrm{Cr}$ contaminated soils, their association with plants and their species diversity may depend on the magnitudes of $\mathrm{Cr}$ stress in the fungi-plant system. For example, Khan (2001) found that Dalbergia sissoo, Acacia arabica, and Populus euroamericana were colonized by a wide variety of AM fungal species from Glomus, Scutellospora, and Araulospora on the non-contaminated (reference) sites, whereas plants on the contaminated sites formed symbiosis only with Gigaspora spp. Besides, high $\mathrm{Cr}$ contents also decreased the species richness and diversity of AM fungi as indicated by decreased Shannon-Weiner index upon Cr contamination (Khan, 2001). Nakatani et al. (2011) also found that tannery waste with high $\mathrm{Cr}$ concentration decreased AM fungal spore density and influenced the mycorrhizal colonization of native plants. These studies showed that $\mathrm{Cr}$ contamination resulted in a selection pressure on AM fungal community in the soils.

2.2 Effects of $\mathrm{Cr}$ stress on $\mathrm{AM}$ symbiosis formation and development

Our previous study (Wu et al., 2014) found that $20 \mathrm{mg} \mathrm{kg}^{-1}$ $\mathrm{Cr}(\mathrm{VI})$ amendment decreased mycorrhizal colonization intensity in roots (M\%) of dandelion (Taraxacum platypecidum Diels.) from $75 \%$ to $50 \%$, and decreased $\mathrm{M} \%$ of bermudagrass (Cynodon dactylon Linn.) from 30\% to 16\%. However, some studies also found that AM fungal colonization was unaffected by $\mathrm{Cr}$ contamination (Nakatani et al., 2011). The influence of metal stress on AM colonization depends on both contamination level and metal(loid) speciation in the soil. Low heavy metal level may stimulate AM symbiosis development, but high concentrations of metal(loid)s limit AM symbiosis development (Chen et al., 2005c; Zhang et al., 2005). In our study on dandelion, $\mathrm{Cr}$ addition below $10 \mathrm{mg} \mathrm{kg}^{-1} \mathrm{Cr}(\mathrm{VI})$ had no influence on mycorrhizal colonization (or even increased $\mathrm{M} \%$ value), while $\mathrm{Cr}$ level above $20 \mathrm{mg} \mathrm{kg}^{-1}$ significantly decreased M\% value (Wu et al., 2014). Estaun et al. (2010) also found that moderate $\mathrm{Cr}$ contamination stimulated mycorrhizal colonization and performance of Plantago lanceolata (Estaun et al., 2010). In addition, $\mathrm{Cr}(\mathrm{III})$ and $\mathrm{Cr}(\mathrm{VI})$ affect AM symbiosis development in different manners (Davies et al., 2001; Arias et al., 2010a; Arias et al., 2010b). For example, Davies et al. (2010) found that mycorrhizal colonization and arbuscule abundance were more affected by $\mathrm{Cr}(\mathrm{VI})$ than $\mathrm{Cr}(\mathrm{III})$ in a soil trial, in which spiking $10 \mathrm{mg} \mathrm{kg}^{-1}$ $\mathrm{Cr}$ (III) only decreased arbuscular abundance (A\%) from $97.3 \%$ to $81.3 \%$, but $1 \mathrm{mg} \mathrm{kg}^{-1} \mathrm{Cr}(\mathrm{VI})$ decreased it from $92 \%$ to $12.3 \%$. It is no doubt that the toxicity of $\mathrm{Cr}(\mathrm{VI})$ in $\mathrm{AM}$ symbiosis development is much higher than $\mathrm{Cr}(\mathrm{III})$, because $\mathrm{Cr}(\mathrm{VI})$ causes much stronger oxidative stress (Shanker et al., 2005). These were consistent with our own experimental findings (Wu et al., 2014). Apart from oxidation status, different metal speciation results in differences in the activity and bioavailability of metal(loid)s, thus differently influencing AM colonization. For instance, Weissenhorn et al. (1995) found that ethylenediaminetetraacetic acid (EDTA)- $\mathrm{NH}_{4} \mathrm{OAc}$ and $\mathrm{Ca}\left(\mathrm{NO}_{3}\right)_{2}$ extractable heavy metal did not influence mycorrhizal colonization, while Leyval et al. (1995) found that $\mathrm{NH}_{4} \mathrm{NO}_{3}$ extractable $\mathrm{Cd}$ and $\mathrm{Zn}$ showed negative effects on AM colonization. The same trends may also work for $\mathrm{Cr}$.

\section{AM effects on plant growth, $\mathrm{Cr}$ uptake and partitioning}

3.1 Effects of AM symbiosis on plant growth and physiology under $\mathrm{Cr}$ contamination

Many studies showed that AM symbiosis improved plant growth in $\mathrm{Cr}$ contaminated soils. For instance, AM symbiosis dramatically enhanced plant growth of dandelion (Cr-sensitive 
plant species) and bermudagrass (Cr-tolerant plant species) in soil contaminated with elevated levels of $\mathrm{Cr}(\mathrm{VI})$, and mycorrhizal dependence increased with increasing $\mathrm{Cr}$ levels of addition (Fig. 1) (Wu et al., 2014). The same type of responses was also found in Helianthus annuus L. in association with Glomus intraradices (Davies et al., 2001), Cannabis sativa in association with G. mosseae (Citterio et al., 2005), P. lanceolata in association with Glomus intraradices (Estaun et al., 2010) and Mesquite plants (Prosopis $\mathrm{sp}$.) in association with Glomus deserticola (Arias et al., 2010a). Besides, AM fungi colonized plants exhibited better physiological traits than those non-mycorrhizal plants, when both exposed to $\mathrm{Cr}$ stress. For instance, mycorrhizal dandelion exhibited higher chlorophyll content in leaves than that of non-mycorrhizal dandelion under $\mathrm{Cr}(\mathrm{VI})$ contamination (Wu et al., 2014), while amylase activity in leaves of plants exposed to $\mathrm{Cr}$ stress decreased upon AM fungal colonization (Arias et al., 2010a). Some studies also showed that mycorrhizal plants had higher chlorophyll content, lower malondialdehyde (MDA) content, lower guaiacol peroxidase (GPX) and ascorbate peroxidase (APX) activity than the nonmycorrhizal plants under $\mathrm{Cr}$ contamination (Davies et al., 2001; Rahmaty and Khara, 2011). The interpretation of $\mathrm{Cr}$ effects on plant physiological traits is closely dependent on $\mathrm{Cr}$ speciation in contaminated soil. AM symbiosis was found to improve $A$. prolifera growth and gas exchange in $\mathrm{Cr}(\mathrm{III})$ treated plants, but not $\mathrm{Cr}(\mathrm{VI})$-treated plants (Singh et al., 2014).

\subsection{Effects of AM symbiosis on plant $\mathrm{Cr}$ uptake and partitioning}

Besides the effects on plant growth and physiology under $\mathrm{Cr}$ stress, AM symbiosis can also influence plant $\mathrm{Cr}$ uptake, accumulation and partitioning. Previous studies indicated that AM symbiosis decreased $\mathrm{Cr}$ concentrations in plants (Davies et al., 2001; Gardezi et al., 2005; Arias et al., 2010a; Arias et al., 2010b; Wu et al., 2014). This effect may be attributed to "growth dilution," as AM symbiosis increased plant biomass. This is similar to AM symbiosis effects on concentrations of other heavy metals in plants, such as $\mathrm{Cu}, \mathrm{Zn}, \mathrm{As}$ and $\mathrm{Cd}$ (Malcová et al., 2003; Ma et al., 2006; Chen et al., 2007a;
Dong et al., 2008). However, in most cases, AM symbiosis increased total plant $\mathrm{Cr}$ uptake, because that AM plants had much higher biomass than nonmycorrhizal plants.

AM symbiosis also influences $\mathrm{Cr}$ partitioning in plants. In a recent study, it was found that $A M$ symbiosis increased root $\mathrm{Cr}$ concentrations, but decreased shoot $\mathrm{Cr}$ concentrations in Medicago truncatula (Wu et al., 2018a). Thus AM symbiosis decreased $\mathrm{Cr}$ translocation from roots to shoots, and lowered Cr toxicity in plant shoots (Wu et al., 2014). Similarly, many studies with other heavy metals (such as $\mathrm{Cu}, \mathrm{Zn}, \mathrm{Pb}, \mathrm{As}$ ) have also showed that AM symbiosis enhanced metal stabilization in roots and limited metal translocation into shoots (Leyval et al., 1997; Christie et al., 2004; Bothe et al., 2010; Wu et al., 2013). The immobilization of heavy metals by AM roots limits $\mathrm{Cr}$ accumulation in shoots, thus relieving $\mathrm{Cr}$ toxicity in leaves. However, in some cases, AM symbiosis was found to have enhanced translocation of metals (including $\mathrm{Cr}$ ) from roots to shoots (Davies et al., 2001, 2002; Citterio et al., 2005), indicating $\mathrm{AM}$ functions toward $\mathrm{Cr}$ partitioning may vary among plant and fungal species.

\subsection{Factors that influence AM functions toward plant Cr uptake and tolerance}

Many factors influence the roles of AM symbiosis in plant $\mathrm{Cr}$ tolerance and uptake, such as plant $\mathrm{P}$ nutrition status, $\mathrm{Cr}$ contamination level, plant and AM fungal species, and soil physicochemical properties. One of the key functions of AM symbiosis is to improve plant phosphorus $(P)$ acquisition, while soil $P$ supply in return significantly influences mycorrhizal formation and development (Karandashov and Bucher, 2005; Chu et al., 2013; Carbonnel and Gutjahr, 2014). Our recent study showed that the effects of AM symbiosis on $\mathrm{Cr}$ tolerance of Medicago truncatula was suppressed by $P$ addition (Wu et al., 2018a). This pattern was also found with As in a study by Zhang et al. (2015), who reported that AM benefits on plant As tolerance became more pronounced under low $\mathrm{P}$ level. In these studies, the improved plant $\mathrm{P}$ nutrition suppresses the development of symbiotic structures (i.e., arbuscules) and associated mycorrhizal functions. Besides, improved $P$ nutrition in plants may also improve plant resistance to metal(loid)s through direct interactions of $P$

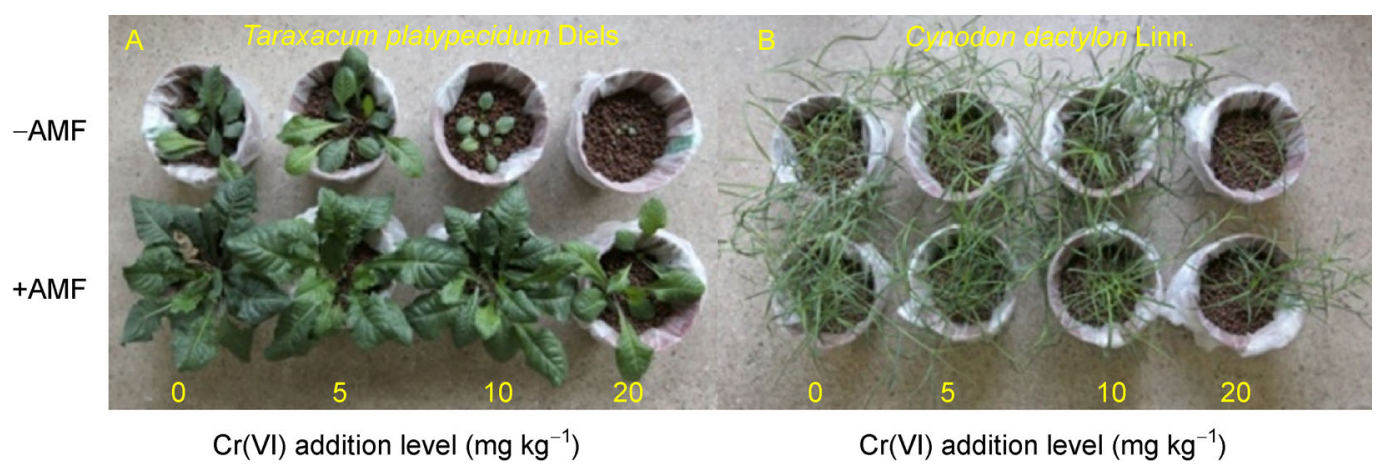

Fig. 1 Pictures of dandelion (Taraxacum platypecidum) (A) and bermudagrass (Cynodon dactylon) (B) grown in soils amended with different $\mathrm{Cr}(\mathrm{VI})$ levels with/without AMF inoculation. "+ AMF" represents inoculation treatment; "-AMF" represents non-inoculation control. 
with metal(loid)s (Du et al., 2014; Singh et al., 2015; Arshad et al., 2016), leading to the reduced dependence of plants on AM symbiosis for surviving the metal contaminated environments.

Chromium is nonessential to plant growth. AM symbiosis lowers $\mathrm{Cr}$ uptake by plants even at very low $\mathrm{Cr}$ concentration in soil. This is contrary to plant uptake of essential metal elements such as $\mathrm{Cu}$ and $\mathrm{Zn}$ to $\mathrm{AM}$ symbiosis. AM symbiosis usually increases plant uptake of $\mathrm{Cu}$ and $\mathrm{Zn}$ under low concentrations, but decreases their uptake at high concentrations in contaminated soil, which has been confirmed by meta analysis (Audet and Charest, 2007).

The functions of AM symbiosis in plant uptake of metals vary among different plant species with different heavy metal tolerance. Our study indicated that AM symbiosis significantly decreased $\mathrm{Cr}$ concentrations in both shoots and roots of dandelion, while showed no influence on that of bermudagregrass (Wu et al., 2014). In comparison, AM symbiosis increased $\mathrm{Pb}$ translocation factor in Kummerowia striata, Ixeris denticulate L. and Ecrusgallivar mitis, while had no effects on that of Lolium perenne L. and Trifolium repens (Chen et al., 2005c). Plant species have no strict specificity for AM fungi, and one plant species may form symbiosis with several AM fungal species (Smith and Read, 2008). However, this does not mean that these AM fungi would have the same functions in the symbiosis with plant roots. Different AM fungal strains may function differently in plant metal uptake and partitioning. For example, in As contaminated soil, Glomus mosseae and Glomus etunicatum decreased shoot As concentrations, while Glomus constrictum had no influence on shoot As concentrations (Yu et al., 2010). Besides, different isolates of the same AM fungal strains may also influence plant metal uptake and tolerance differently. For instance, G. mosseae isolated from Cd contaminated soils increased shoot $\mathrm{Cd}$ concentration in Trifolium repens, while $\mathrm{G}$. mosseae isolated from non-polluted soils had no influence on plant Cd uptake (Biro et al., 2009). Based on the above studies on As and $\mathrm{Cd}$, it is expected that different AM fungal species influence plant $\mathrm{Cr}$ uptake and tolerance differently.

Soil physicochemical characteristics can also influence AM functions. For instance, soil $\mathrm{pH}$ influences $\mathrm{AM}$ functions through influencing AM symbiosis development, as AM fungi and their association with plants may vary with different soil $\mathrm{pH}$ (Coughlan et al., 2000). For example, Glomus spp. prefer pH 5-9, while Acaulospora, Gigaspora, Scutellospora spp. are more active at $\mathrm{pH}<7$ (Yu and Zhao, 2008).

\section{Mechanisms underlying the enhanced plant $\mathrm{Cr}$ tolerance by AM symbiosis}

AM symbiosis can improve plant performance under $\mathrm{Cr}$ contamination through direct and indirect pathways. In the direct way, AM symbiosis influences $\mathrm{Cr}$ behavior in the rhizosphere or plant roots and thus influences its uptake and toxicity; in the indirect way, AM symbiosis indirectly enhances plant resistance to $\mathrm{Cr}$ stress through improvement of plant nutrition or regulation of $\mathrm{Cr}$ defense system in host plants.
4.1 Direct involvements of AM fungi in $\mathrm{Cr}$ translocation and transformation

\subsection{1 $\mathrm{Cr}$ bioavailability changes in the mycorrhizosphere}

AM fungi influence rhizosphere micro-environment through exudation of low molecular weight acids (LMWA) or glomalin related soil protein (GRSP-a glycoprotein with repeated monomeric structures), altering metal bioavailability. In addition, exudates (e.g., GRSP) may also complex with metals, thus influencing metal speciation. For example, acid-extractable $\mathrm{Cr}$ concentration in the rhizosphere decreased in soils with AM fungal inoculation (Wu et al., 2014). Similarly, studies on $\mathrm{Pb}$ and $\mathrm{Zn}$ showed that $\mathrm{AM}$ symbiosis increased organic combined $\mathrm{Zn}$ concentration, while decreased crystalline and residue $\mathrm{Zn}$ concentrations (Subramanian et al., 2009), increased exchangeable $\mathrm{Pb}$ and organic $\mathrm{Pb}$ but decreased $\mathrm{Fe} / \mathrm{Mn}$ oxidized $\mathrm{Pb}$ and cabonate $\mathrm{Pb}$ in soils (Zhang et al., 2012).

GRSP has a great potential in complexation of heavy metals, such as $\mathrm{Cr}, \mathrm{Cu}, \mathrm{Pb}$ and $\mathrm{Zn}$ (Nichols, 2003; GonzálezChávez et al., 2004). For example, Gil-Cardeza et al. (2014) investigated GRSP concentrations and their relationship with $\mathrm{Cr}$ in a $\mathrm{Cr}$ contaminated industrial and urban soil and found that much $\mathrm{Cr}(\mathrm{III})$ was complexed with total glomalin related protein (T-GRSP), indicating the possible role of GRSP in stabilization of $\mathrm{Cr}$ in the soil. Cornejo et al. (2008) found that GRSP in the rhizosphere showed a positive relationship with $\mathrm{Cu}$ and $\mathrm{Zn}$ concentrations in the soil. Besides, GRSP-Cu in the soils accounted for $1.4 \%-27.5 \%$ of the total Cu (Cornejo et al., 2008). Vodnik et al. (2008) found that GRSP-complexed pool contained $690-23400 \mathrm{mg} \mathrm{kg}^{-1} \mathrm{~Pb}$, accounting for $0.8 \%-$ $15.5 \%$ of the total $\mathrm{Pb}$ in the soil.

GRSP complexation with metals may be attributed to strong chemical bonding rather than electrostatic adsorption. González-Chávez et al. (2004) found that GRSP was tightly bound with $\mathrm{Cu}$, which could not be broken down by $50 \mathrm{mM}$ citric acids, boric acid or chloride acid. However, the traditional method of extraction has their drawbacks, as extraction process may also cause metal transformation. These limitations of conventional methods can be overcome by in situ analysis of metal speciation in the rhizosphere using advanced spectroscopic methods such as synchrotron based X-ray florescence spectroscopy (XRF) and X-ray absorption spectroscopy (XAS).

4.1.2 $\mathrm{Cr}$ translocation and transformation in plant roots as influenced by AM symbiosis

AM fungi influence metal distribution and speciation, consequently alleviating metal phytotoxicity. Arias et al. (2010b) found that mycorrhizal inoculation favored $\mathrm{Cr}$ accumulation in the vascular system, and reduced $\mathrm{Cr}$ translocation into shoots. By using synchrotron based X-ray fluorescence microscopy (micro-XRF), Wu et al. (2016a) revealed that AM symbiosis altered $\mathrm{Cr}$ distribution in main roots, resulting in Cr distribution mainly in epidomeris of the mycorrhizal roots, in 
contrast to nonmycorrhizal roots in which $\mathrm{Cr}$ was mainly distributed in vascular bundles. These suggest that mycorrhizal symbiosis may reduce $\mathrm{Cr}$ transport from lateral roots to main roots, and subsequent $\mathrm{Cr}$ transport from roots to shoots. Chromium was found to be transported from roots to shoots via vascular bundles (Skeffington et al., 1976). This may explain why AM symbiosis decreased $\mathrm{Cr}$ translocation factor (Wu et al., 2016a).

A further study indicated that mycorrhizal fungi compartmented $\mathrm{Cr}$ in fungal structures inside the roots by using synchrotron based scanning transmission soft X-ray microscopy (STXM) (Wu et al., 2016b). Chromium may be retained in fungal structures, resulting in reduced amount of $\mathrm{Cr}$ transport from fungi to cytoplasm of plant cells and lowered $\mathrm{Cr}$ phytotoxicity. Further study showed that $\mathrm{Cr}$ was possibly complexed with phosphate or histidine inside the fungal structures as revealed by synchrotron based XAS (Wu et al., $2016 b)$. AM symbioses are well known to be functional in assisting plant $P$ acquisition because mycelium assist $P$ absorption from distance and transport it into arbuscules (the symbiotic interface between plants and AM fungi) (Kuga et al., 2008). As a result, it may be hypothesized that phosphate may precipitate $\mathrm{Cr}$, contributing to the retention of $\mathrm{Cr}$ in fungal structures.

Apart from $\mathrm{Cr}$, many cation metals (such as $\mathrm{Cu}, \mathrm{Cd}, \mathrm{Pb}$ and $\mathrm{Zn}$ ) were also found to be precipitated in fungal structures within plant roots. For instance, as revealed by synchrotron based micro-XRF, Nayuki et al. (2014) and Chen et al. (2018) found that $\mathrm{Cd}$ mainly accumulated in fungal structures inside mycorrhizal roots. Some studies even found that $U$ was located in intraradical mycelia or vesicles inside mycorrhizal roots (Weiersbye et al., 1999). By using Particle-induced Xray emission (PIXE), Orłowska et al. (2011) also found that $\mathrm{Ni}$ was accumulated in fungal structures inside $\mathrm{AM}$ roots of a $\mathrm{Ni}$ hyperaccumulator (Berkheya coddii Roessler). A recent study by Wu et al. (2018b) observed that $Z n$ was mainly immobilized by arbuscules in the mycorrhizal maize roots grown in $\mathrm{Zn} / \mathrm{Pb}$ contaminated soils. These studies collectively revealed that mycorrhizal stabilization of heavy metals may be a common strategy for plants capable of forming AM symbiosis to tolerate heavy metals in soil.

In addition, AM symbiosis also influences $\mathrm{Cr}$ transformation in plants through redox changes to reduce $\mathrm{Cr}(\mathrm{VI})$ to $\mathrm{Cr}(\mathrm{III})$ once being taken up by roots. In most studies, $\mathrm{Cr}$ (III) was found to be the main $\mathrm{Cr}$ species inside the plant roots, which is present in the form of $\mathrm{Cr}(\mathrm{III})$-carboxyl groups (Aldrich et al., 2003). AM symbiosis may also further influence $\mathrm{Cr}$ (III) speciation inside roots by decreasing the percentage of $\mathrm{Cr}$ (III)-systeine and $\mathrm{Cr}(\mathrm{III})$-acetate analogs, while increasing the proportions of $\mathrm{Cr}(\mathrm{III})$-phosphate and $\mathrm{Cr}$ (III)-histidine (Wu et al., 2018a). The changes in $\mathrm{Cr}$ speciation in roots by $\mathrm{AM}$ symbiosis may have resulted from direct involvement of fungal structures or the stimulation of root metabolism by AM symbiosis. In summary, $\mathrm{Cr}$ in the mycorrhizal roots tended to exist in a more stable form than that in nonmycorrhizal roots, enhancing $\mathrm{Cr}$ stabilization in roots and contributing to the enhanced plant $\mathrm{Cr}$ tolerance. Similar roles of AM symbiosis in metal transformation in plants were also reported for As. For instance, AM symbiosis can facilitate Dimethylarsinic acid (DMA) formation in plant shoots (Zhang et al., 2015). Yu et al. (2009) also found that AM symbiosis can restrain As(V) reduction to $A s(\mathrm{III})$, and reduce $\mathrm{As}$ (III) concentrations, which may due to the decreased activity of As reduction enzymes.

\subsubsection{Cr uptake and stabilization by extraradical mycelium}

The formation of AM symbiosis leads to the production of extensive extraradical mycelia in rhizosphere. The mycelium is usually much finer than roots, with a diameter of up to several micrometers, possessing high capacity to absorb nutrients and heavy metals. By using a three-compartment cultivation system, it was demonstrated that extraradical mycelium (ERM) absorbed and transported $\mathrm{Cr}$ to mycorrhizal roots from distance, but might not translocate these $\mathrm{Cr}$ from roots to shoots, and therefore contributed to $\mathrm{Cr}$ stabilization in roots and relieved $\mathrm{Cr}$ phytotoxicity (Wu et al., 2016a).

By using a compartmented root-organ cultivation system (Fig. 2A), we found that $\mathrm{Cr}$ can be taken up by $\mathrm{AM}$ fungal mycelium and transported to mycorrhizal roots (Wu et al., 2015). To further study whether the uptake of $\mathrm{Cr}$ by mycelium was active or passive, we inhibited the activity of mycelia by formadehyde or 2,4-dinitrophenol (DNP). Interestingly, we found that the limitation of fungal myceliuim activities resulted lowered $\mathrm{Cr}$ uptake and transport by mycelium. These suggest that the uptake and transport of $\mathrm{Cr}$ was mainly via an active uptake pathway.

Other studies also found that AM fungal mycelia actively took up and transported Zn (Chen et al., 2003), As (Chen et al., 2007b), and even U (Rufyikiri et al., 2003). The uptake of nonessential heavy metals is mainly through the transporters for essential nutrients. For instance, fungi take up As(V) through $\mathrm{P}$ transporters (Catarecha et al., 2007) and $\mathrm{Cr}(\mathrm{VI})$ through sulfate transporters (de María Guillén-Jiménez et al., 2008; Holland and Avery, 2011) or phosphate transporters (de Oliveira et al., 2015).

Although AM mycelia take up significant amounts of metals, the absorbed metals may not be completely transported into root cells. This may be due to the compartmentation of metals by fungal structures inside roots, or due to stabilization of metals by extraradical mycelium. In fact, some studies found that mycelium had a great capacity to immobilize heavy metals (e.g., Cu, Zn) (Chen et al., 2001). Similarly, by using root-organ cultivation system, it was found that $70 \%$ of $\mathrm{Cr}$ taken up by AM fungi was stabilized in extraradical mycelium, leading to reduced $\mathrm{Cr}$ transport to roots and alleviated $\mathrm{Cr}$ phytotoxicity (Wu et al., 2015).

\subsection{4 $\mathrm{Cr}$ translocation and transformation by AM fungal mycelium}

After absorption by AM fungi, $\mathrm{Cr}(\mathrm{VI})$ can be completely reduced to $\mathrm{Cr}(\mathrm{III})$, which is catalyzed by chromate enzyme activities or some molecules (such as carboxyl groups, thiols) 


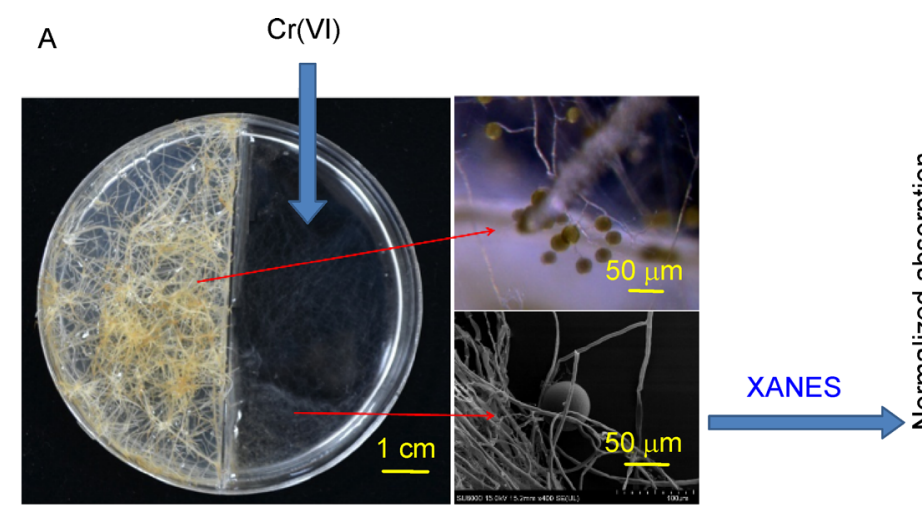

B

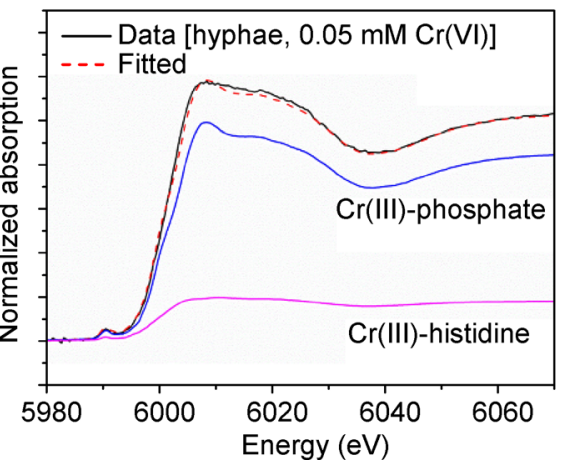

Fig. 2 Diagram showing uptake and transport of $\mathrm{Cr}$ by $\mathrm{AM}$ fungal mycelium in a root-organ cultivation system (A), as well as the $\mathrm{Cr}$ speciation in AM fungal mycelium as revealed by synchrotron based X-ray absorption near edge spectroscopy (XANES) analysis (B).

acting as electron acceptors (Wu et al., 2015). However, when the metabolic activity was limited by DNP or $\mathrm{HCHO}, \mathrm{Cr}(\mathrm{VI})$ may be completely reduced to $\mathrm{Cr}(\mathrm{III})$ in 4 days interaction with mycelium. This indicates that $\mathrm{Cr}(\mathrm{VI})$ may also be reduced partially and non-metabolically.

The XAFS analysis further showed that $\mathrm{Cr}$ (III) was subsequently precipitated mainly by phosphate analogs and $\mathrm{Cr}$ (III) histidine (Fig. 2B). Further examination using STXM indicated that those $\mathrm{Cr}$ may precipitate on mycelium surface as particles (Wu et al., 2016b), in which $\mathrm{Cr}$ correlated with $\mathrm{P}$. Chromium $\mathrm{K}$ edge XAFS confirmed that phosphate contributed to $\mathrm{Cr}$ stabilization on mycelium surface (Wu et al., $2016 \mathrm{~b}$ ). When the mycelium activity was inhibited by DNP or $\mathrm{HCHO}, \mathrm{Cr}$ (III)-histidine in mycelia tended to disappear (Wu et al., 2015). This suggests that that $\mathrm{Cr}$ (III)-histidine analogs may exist inside the living hyphae or fungal structures in roots (i.e. arbuscules, intraradical mycelium, vesicles etc.). $\mathrm{Cr}$ (III) may be transported in the form of $\mathrm{Cr}(\mathrm{III})$-histidine in the mycelium. This is in contrast to $\mathrm{Cr}$ (III)-phosphate which precipitates on hyphal surface. This may be due to the functions of extracellular polymeric substances (EPS) exudated by the fungi. In a recent study, we found that AM fungi produced numerous EPS on the mycelium surface upon $\mathrm{Cr}(\mathrm{VI})$ stress and $\mathrm{Cr}$ mainly existed in these EPS (Wu et al., 2016b). These suggested that EPS potentially contributed to $\mathrm{Cr}(\mathrm{VI})$ reduction and immobilization on fungal surface. Taken together the results of STXM and XAFS analysis, it is concluded that AM fungi can adsorb and reduce $\mathrm{Cr}(\mathrm{VI})$ to $\mathrm{Cr}(\mathrm{III})$, and complex $\mathrm{Cr}$ (III) mainly by phosphate groups on mycelium surface resulting from EPS produced by AM fungi in response to $\mathrm{Cr}$ (VI) stress. Beside, a small proportion of $\mathrm{Cr}$ may be taken up and transported into fungal structures inside roots possibly in the form of $\mathrm{Cr}(\mathrm{III})$-histidine. Other heavy metals can exist in the vesicles and cell walls of the fungi (Weiersbye et al., 1999; González-Guerrero et al., 2008). By using Energy-dispersive X-ray spectroscopy (EDS), González-Guerrero et al. (2008) found that either in spores or mycelium, metal was accumulated in cell walls, but less in cytoplasm (González-Guerrero et al., 2008). Further study should pay more attention to subcellular $\mathrm{Cr}$ localization and speciation in the AM symbiosis.

\subsection{Indirect involvements of AM fungi in plant $\mathrm{Cr}$ tolerance}

4.2.1 AM symbiosis improves plant mineral nutrition under $\mathrm{Cr}$ contamination

Cr stress may reduce plant nutrient uptake and cause nutrient deficiency, because $\mathrm{Cr}$ uptake competes for transporters of essential nutrients, such as sulfate and phosphate transporters (Holland and Avery, 2011). For examples, $\mathrm{Cr}(\mathrm{VI})$ exposure may result in $\mathrm{S}$ or $\mathrm{P}$ deficiencies (Pereira et al., 2008; de Oliveira et al., 2015). However, AM fungi may assist nutrient uptake by plants, such as $P$ (Karandashov and Bucher, 2005), N (Govindarajulu et al., 2005), or S (Allen and Shachar-Hill, 2009), alleviating nutrient deficiency in infertile soil. In fact, we found that AM symbiosis can dramatically increase $\mathrm{P}$ and $\mathrm{S}$ and $\mathrm{N}$ concentrations in plants under $\mathrm{Cr}(\mathrm{VI})$ contaminations (Wu et al., 2014). The improvement of nutrition status of plants by AM symbiosis may enhance plant tolerance to Cr toxicity. For example, Chen et al. (2007) found that the mycelium of $G$. mosseae preferred to take up P over As (Chen et al., 2007b). While at the same time, under $U$ contamination AM mycelium improved $P$ uptake by barley plants from phosphate rock containing $U$ (Chen et al., 2005b). In most cases, AM symbiosis enhances plant growth through increasing nutrient uptake, resulting in reduced metal concentrations in plants, generating "growth dilution effects" (Chen et al., 2007a; Dong et al., 2008).

4.2.2 AM symbiosis regulates plant physiological and molecular processes for $\mathrm{Cr}$ detoxification

AM symbiosis may regulate molecular or physiological processes in plants to deal with $\mathrm{Cr}$ stress. Heavy metals usually cause oxidative stress by producing reactive oxygen species (ROS), while AM symbiosis may stimulate antioxidative processes in plants and thus help plant surviving 
heavy metal stress (Yang et al., 2015; Azcón et al., 2009). Our recent study showed that AM symbiosis dramatically upregulated expression of high affinity sulfate transporter genes MtSULTR1.1 and MtSULTR1.2 in roots of Medicago trunctula plants and improved $\mathrm{S}$ uptake by plants under $\mathrm{Cr}(\mathrm{VI})$ contamination. Besides, AM symbiosis also systematically regulated $S$ metabolism as one of the mechanisms of $\mathrm{Cr}$ detoxification, contributing to the relief of oxidative stress caused by $\mathrm{Cr}(\mathrm{VI})$ (Wu et al., 2018a). Similarly, some studies also found that AM symbiosis increased NP-SH, GSH and PCs levels in plants, which complexed with heavy metals and alleviated metal toxicity (Garg and Chandel, 2012). By proteomic analysis, some studies (Repetto et al., 2003; Aloui et al., 2009) also found that AM symbiosis systematically regulated functional proteins (e.g., annexin or cyclophilin etc.) to enhance plant tolerance to $\mathrm{Cd}$ through various ways including alleviate oxidative stress. As $\mathrm{Cr}$ causes oxidative stress, it is expected that AM symbiosis may also regulate plant metabolisms to alleviate Cr toxicity.

In conclusion, AM fungi play an important role in plant $\mathrm{Cr}$ tolerance. On one hand, AM fungi can directly immobilize $\mathrm{Cr}$ in the rhizosphere, or stabilize $\mathrm{Cr}$ in fungal structures through precipitation of $\mathrm{Cr}$ on fungal surface or compartmentation of $\mathrm{Cr}$ in fungal structures inside plant roots. Histidine and phosphate may be the main groups that contribute to the mechanisms of AM fungi to detoxify $\mathrm{Cr}$ in plants. On the other hand, AM symbiosis can indirectly enhance plant tolerance to $\mathrm{Cr}$ through improvement of plant mineral nutrition status or through regulation of physiological and molecular processes of plants to enhance plant capacity to resist $\mathrm{Cr}$ (Fig. 3).

\section{Perspectives}

(1) Revealing physiological and molecular mechanisms underlying $\mathrm{Cr}$ behavior and detoxification in AM symbiosis

Previous studies have uncovered the processes of $\mathrm{Cr}$ translocation and immobilization by AM symbiosis. However, the molecular mechanisms controlling the translocation and transformation of $\mathrm{Cr}$ in the symbiotic interface remain unclear. Further investigations are required to unravel the way by which AM fungi take up $\mathrm{Cr}(\mathrm{VI})$ or $\mathrm{Cr}(\mathrm{III})$ and associated transporters, as well as the physiological and molecular mechanisms underlying the $\mathrm{Cr}$ tolerance of $\mathrm{AM}$ fungi. In future, the combined use of advanced microspectroscopic methods (such as synchrotron based XRF, XAS, STXM and NanoSIMS etc.) with newly developed physiological and molecular technologies (such as advanced transcriptomics, proteomics and metabolomics) will be of great value for uncovering the mechanisms of $\mathrm{Cr}$ behavior at the symbiotic interface, as well as the mechanisms of $\mathrm{Cr}$ tolerance of $\mathrm{AM}$ fungi.

(2) Potential use of AM fungi in ecological restoration and agriculture production in $\mathrm{Cr}$ contaminated soils

Considering the important role of AM symbiosis in plant $\mathrm{Cr}$ tolerance (Davies et al., 2001; Wu et al., 2014), AM fungi would be of great value in revegetation or phytostabilization of

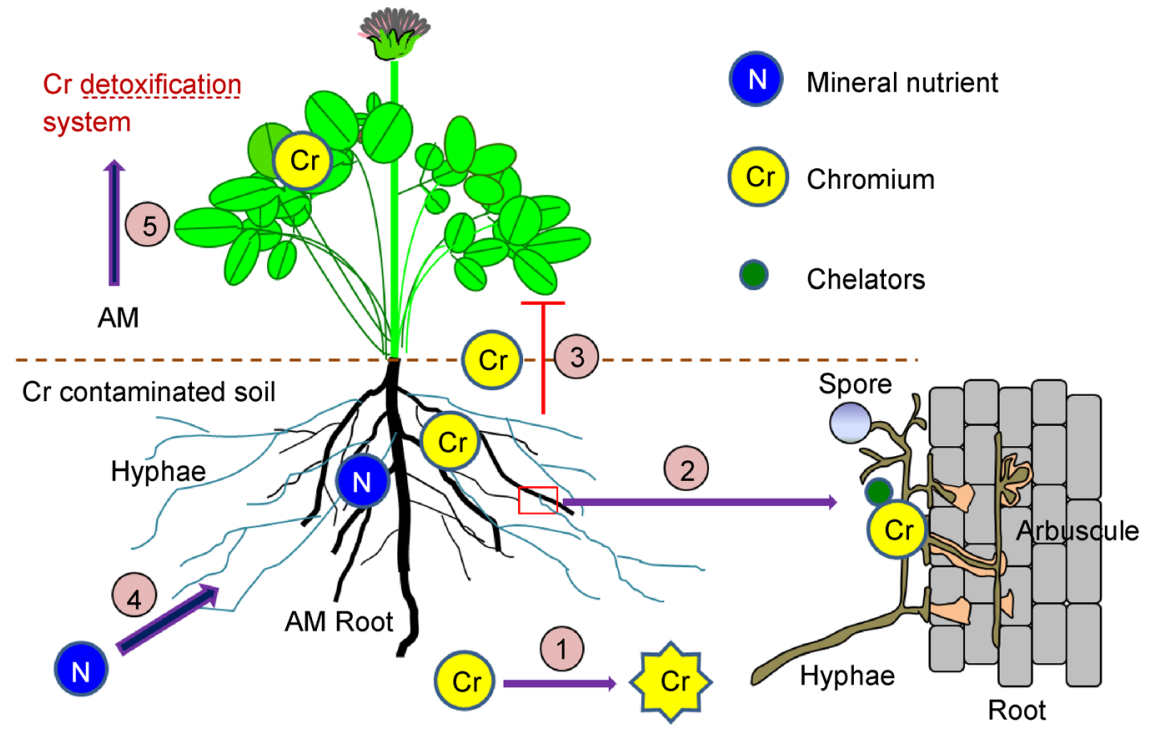

Fig. 3 Schematic representation of mechanisms underlying the enhanced plant tolerance to $\mathrm{Cr}$ by AM symbiosis. Key processes controlling $\mathrm{Cr}$ transformation and translocation are indicated by numbers. "1" represents the complexation of heavy metal by secretions (such as glomalin, or small acid organic compounds) produced by mycorrhizal roots, or alters metal speciation and bioavailability through influencing chemical characteristics of rhizosphere soils; "2" represents the immobilization of $\mathrm{Cr}$ in AM fungal structures including extra- and intraradical fungal structures (e.g. mycelium, arbuscules, vesicles, etc) via complexation with phosphate nitrogenous or carboxylic ligands; "3" represent the reduced $\mathrm{Cr}$ translocation from roots to shoots by AM symbiosis; "4" represents that AM symbiosis assists plant nutrient acquisition (such as phosphorus, nitrogen and sulfur uptake); " 5 " represents the AM regulated molecular or physiological processes in plants for $\mathrm{Cr}$ detoxification. 
Cr contaminated soils. As AM fungal structures can stabilize $\mathrm{Cr}$ in the soils and reduce Cr mobility (Wu et al., 2015; Wu et al., 2016b), therefore AM fungi also has a great potential in assisting phytostabilization of $\mathrm{Cr}$. In addition, AM symbiosis favors rhizosphere microbial communities, accelerating the recovery of rhizosphere ecosystem (Johansson et al. ,2004; Miransari, 2011). From these benefits, AM fungi may be used in improving safe agricultural production in $\mathrm{Cr}$ contaminated farmlands, as it can decrease $\mathrm{Cr}$ translocation from roots to shoots and reduce $\mathrm{Cr}$ accumulation in edible parts of crops (Wu et al., 2014; Wu et al., 2016a). However, most previous studies have been conducted in the laboratory (highly artificial growing conditions), while few studies focused on the AM fungal functions in the field. In fact, due to complex climate and soil chemical/biological conditions in the field, the results of glasshouse work may not be easily extended into the field practices. For example, Dietterich et al. (2017) found in a field experiments that AM colonization had little effects on plant heavy metal uptake, which was much different from many previous laboratory work. Therefore, future studies should further investigate the role of AM fungi in plant surviving $\mathrm{Cr}$ contamination under field conditions.

\section{Acknowledgments}

This study was supported by National Key Research and Development Program of China (2016YFD0800400) and the National Natural Science Foundation of China (21677164).

\section{References}

Al-Ghamdi, A.A.M., Jais, H.M., 2012. Interaction between arbuscular mycorrhiza and heavy metals in the rhizosphere and roots of Juniperus procera. International Journal of Agriculture and Biology 14, 69-74.

Aldrich, M.V., Gardea-Torresdey, J.L., Peralta-Videa, J.R., Parsons, J. G., 2003. Uptake and reduction of $\mathrm{Cr}(\mathrm{VI})$ to $\mathrm{Cr}(\mathrm{III})$ by mesquite (Prosopis spp.): chromate-plant interaction in hydroponics and solid media studied using XAS. Environmental Science \& Technology 37, 1859-1864.

Allen, J.W., Shachar-Hill, Y., 2009. Sulfur transfer through an arbuscular mycorrhiza. Plant Physiology 149, 549-560.

Aloui, A., Recorbet, G., Gollotte, A., Robert, F., Valot, B., GianinazziPearson, V., Aschi-Smiti, S., Dumas-Gaudot, E., 2009. On the mechanisms of cadmium stress alleviation in Medicago truncatula by arbuscular mycorrhizal symbiosis: a root proteomic study. Proteomics 9, 420-433.

Appenroth, K.J., Bischoff, M., Gabryś, H., Stoeckel, J., Swartz, H.M., Walczak, T., Winnefeld, K., 2000. Kinetics of chromium(V) formation and reduction in fronds of the duckweed Spirodela polyrhiza-a low frequency EPR study. Journal of Inorganic Biochemistry 78, 235-242.

Arias, J.A., Peralta-Videa, J.R., Ellzey, J.T., Ren, M., Viveros, M.N., Gardea-Torresdey, J.L., 2010a. Effects of Glomus deserticola inoculation on Prosopis: Enhancing chromium and lead uptake and translocation as confirmed by X-ray mapping, ICP-OES and TEM techniques. Environmental and Experimental Botany 68, 139-148.

Arias, J.A., Peralta-Videa, J.R., Ellzey, J.T., Viveros, M.N., Ren, M., Mokgalaka-Matlala, N.S., Castillo-Michel, H., Gardea-Torresdey, J. L., 2010b. Plant growth and metal distribution in tissues of Prosopis juliflora-velutina grown on chromium contaminated soil in the presence of Glomus deserticola. Environmental Science \& Technology 44, 7272-7279.

Arshad, M., Ali, S., Noman, A., Ali, Q., Rizwan, M., Farid, M., Irshad, M.K., 2016. Phosphorus amendment decreased cadmium (Cd) uptake and ameliorates chlorophyll contents, gas exchange attributes, antioxidants, and mineral nutrients in wheat (Triticum aestivum L.) under Cd stress. Archives of Agronomy and Soil Science 62, 533-546.

Audet, P., Charest, C., 2007. Dynamics of arbuscular mycorrhizal symbiosis in heavy metal phytoremediation: meta-analytical and conceptual perspectives. Environmental Pollution 147, 609-614.

Azcón, R., del Carmen Perálvarez, M., Biro, B., Roldán A., RuízLozano J. M., 2009. Antioxidant activities and metal acquisition in mycorrhizal plants growing in a heavy-metal multicontaminated soil amended with treated lignocellulosic agrowaste. Applied Soil Ecology 41, 168-177.

Biro, I., Nemeth, T., Takacs, T., 2009. Changes of parameters of infectivity and efficiency of different Glomus mosseae arbuscular mycorrhizal fungi strains in cadmium-loaded soils. Communications in Soil Science and Plant Analysis 40, 227-239.

Bothe, H., Regvar, M., Turnau, K., 2010. Arbuscular mycorrhiza, heavy metal, and salt tolerance. In: Sherameti I and Varma A (ed.) Soil Heavy Metals, Springer, Berlin Heidelberg, pp 87-111.

Carbonnel, S., Gutjahr, C., 2014. Control of arbuscular mycorrhiza development by nutrient signals. Frontiers of Plant Science 5, 462.

Catarecha, P., Segura, M.D., Franco-Zorrilla, J.M., García-Ponce, B., Lanza, M., Solano, R., Paz-Ares, J., Leyva, A., 2007. A mutant of the Arabidopsis phosphate transporter PHT1;1 displays enhanced arsenic accumulation. Plant Cell 19, 1123-1133.

Chen, B., Nayuki, K., Kuga, Y., Zhang, X., Wu, S., Ohtomo, R., 2018. Uptake and intraradical immobilization of cadmium by arbuscular mycorrhizal fungi as revealed by a stable isotope tracer and synchrotron radiation $\mu \mathrm{X}$-ray fluorescence analysis. Microbes and Environments 33, 257-263.

Chen, B., Roos, P., Borggaard, O.K., Zhu, Y.G., Jakobsen, I., 2005b. Mycorrhiza and root hairs in barley enhance acquisition of phosphorus and uranium from phosphate rock but mycorrhiza decreases root to shoot uranium transfer. New Phytologist 165, 591-598.

Chen, B., Tang, X., Zhu, Y., Christie, P., 2005a. Metal concentrations and mycorrhizal status of plants colonizing copper mine tailings: potential for revegetation. Science in China Series C 48, 156-164.

Chen, B., Xiao, X., Zhu, Y.G., Smith, F.A., Xie, Z.M., Smith, S.E., 2007b. The arbuscular mycorrhizal fungus Glomus mosseae gives contradictory effects on phosphorus and arsenic acquisition by Medicago sativa Linn. Science of the Total Environment 379, 226 234.

Chen, B.D., Li, X.L., Tao, H.Q., Christie, P., Wong, M.H., 2003. The role of arbuscular mycorrhiza in zinc uptake by red clover growing 
in a calcareous soil spiked with various quantities of zinc. Chemosphere 50, 839-846.

Chen, B.D., Zhu, Y.G., Duan, J., Xiao, X.Y., Smith, S.E., 2007a. Effects of the arbuscular mycorrhizal fungus Glomus mosseae on growth and metal uptake by four plant species in copper mine tailings. Environmental Pollution 147, 374-380.

Chen, X., Wu, C., Tang, J., Hu, S., 2005c. Arbuscular mycorrhizae enhance metal lead uptake and growth of host plants under a sand culture experiment. Chemosphere 60, 665-671.

Christie, P., Li, X., Chen, B., 2004. Arbuscular mycorrhiza can depress translocation of zinc to shoots of host plants in soils moderately polluted with zinc. Plant and Soil 261, 209-217.

Chu, Q., Wang, X., Yang, Y., Chen, F., Zhang, F., Feng, G., 2013. Mycorrhizal responsiveness of maize (Zea mays L.) genotypes as related to releasing date and available $\mathrm{P}$ content in soil. Mycorrhiza 23, 497-505.

Citterio, S., Prato, N., Fumagalli, P., Aina, R., Massa, N., Santagostino, A., Sgorbati, S., Berta, G., 2005. The arbuscular mycorrhizal fungus Glomus mosseae induces growth and metal accumulation changes in Cannabis sativa L. Chemosphere 59, 21-29.

Cornejo, P., Meier, S., Borie, G., Rillig, M.C., Borie, F., 2008. Glomalinrelated soil protein in a Mediterranean ecosystem affected by a copper smelter and its contribution to $\mathrm{Cu}$ and $\mathrm{Zn}$ sequestration. Science of the Total Environment 406, 154-160.

Coughlan, A.P., Dalpe, Y., Lapointe, L., Piché, Y., 2000. Soil pHinduced changes in root colonization, diversity, and reproduction of symbiotic arbuscular mycorrhizal fungi from healthy and declining maple forests. Canadian Journal of Forest Research 30, 15431554.

Davies, F.T. Jr, Puryear, J.D., Newton, R.J., Egilla, J.N., Saraiva Grossi, J.A., 2001. Mycorrhizal fungi enhance accumulation and tolerance of chromium in sunflower (Helianthus annuus). Journal of Plant Physiology 158, 777-786.

Davies, F.T. Jr, Puryear, J.D., Newton, R.J., Egilla, J.N., Saraiva Grossi, J.A., 2002. Mycorrhizal fungi increase chromium uptake by sunflower plants: Influence on tissue mineral concentration, growth, and gas exchange. Journal of Plant Nutrition 25, 2389 2407.

de María Guillén-Jiménez, F., Morales-Barrera, L., Morales-Jiménez, J., Hernández-Rodríguez, C.H., Cristiani-Urbina, E., 2008. Modulation of tolerance to $\mathrm{Cr}(\mathrm{VI})$ and $\mathrm{Cr}(\mathrm{VI})$ reduction by sulfate ion in a Candida yeast strain isolated from tannery wastewater. Journal of Industrial Microbiology \& Biotechnology 35, 1277-1287.

de Oliveira, L.M., Lessl, J.T., Gress, J., Tisarum, R., Guilherme, L.R. G., Ma, L.Q., 2015. Chromate and phosphate inhibited each other's uptake and translocation in arsenic hyperaccumulator Pteris vittata L. Environmental Pollution 197, 240-246.

Dietterich, L.H., Gonneau, C., Casper, B.B., 2017. Arbuscular mycorrhizal colonization has little consequence for plant heavy metal uptake in contaminated field soils. Ecological Applications 27, 1862-1875.

Dong, Y., Zhu, Y.G., Smith, F.A., Wang, Y., Chen, B., 2008. Arbuscular mycorrhiza enhanced arsenic resistance of both white clover (Trifolium repens Linn.) and ryegrass (Lolium perenne L.) plants in an arsenic-contaminated soil. Environmental Pollution 155, 174 181.
Du, J., Yan, C., Li, Z., 2014. Phosphorus and cadmium interactions in Kandelia obovata (S. L.) in relation to cadmium tolerance. Environmental Science and Pollution Research International 21, 355-365.

Estaun, V., Cortes, A., Velianos, K., Camprubí, A., Calvet, C., 2010. Effect of chromium contaminated soil on arbuscular mycorrhizal colonisation of roots and metal uptake by Plantago lanceolata. Spanish Journal of Agricultural Research 8, S109-S115.

Ferrol, N., Tamayo, E., Vargas, P., 2016. The heavy metal paradox in arbuscular mycorrhizas: from mechanisms to biotechnological applications. Journal of Experimental Botany 67, 6253-6265.

Gardezi, A.K., Barceló-Quintal, I.D., Cetina-Alcalá, V.M., et al, (2005) Phytoremediation by Leucaena leucocephala in association with arbuscular endomycorrhiza and rhizobium in soil polluted by $\mathrm{Cr}$. In: Callaos et al (ed) The 9th World Multiconference on Systemics, Cybernetics and Informatics. Orlando, Florida, USA, pp 289-298.

Garg, N., Chandel, S., 2012. Role of Arbuscular mycorrhizal (AM) fungi on growth, cadmium uptake, osmolyte, and phytochelatin synthesis in Cajanus cajan (L.) Millsp under $\mathrm{NaCl}$ and Cd stresses. Journal of Plant Growth Regulation 31, 292-308.

Gil-Cardeza, M.L., Ferri, A., Cornejo, P., Gomez, E., 2014. Distribution of chromium species in a Cr-polluted soil: presence of $\mathrm{Cr}$ (III) in glomalin related protein fraction. Science of the Total Environment 493, 828-833.

González-Chávez, M.C., Carrillo-González, R., Gutiérrez-Castorena, M.C., 2009. Natural attenuation in a slag heap contaminated with cadmium: the role of plants and arbuscular mycorrhizal fungi. Journal of Hazardous Materials 161, 1288-1298.

González-Chávez, M.C., Carrillo-González, R., Wright, S.F., Nichols, K.A., 2004. The role of glomalin, a protein produced by arbuscular mycorrhizal fungi, in sequestering potentially toxic elements. Environmental Pollution 130, 317-323.

González-Guerrero, M., Melville, L.H., Ferrol, N., Lott, J.N., AzcónAguilar, C., Peterson, R.L., 2008. Ultrastructural localization of heavy metals in the extraradical mycelium and spores of the arbuscular mycorrhizal fungus Glomus intraradices. Canadian Journal of Microbiology 54, 103-110.

Govindarajulu, M., Pfeffer, P.E., Jin, H., Abubaker, J., Douds, D.D., Allen, J.W., Bücking, H., Lammers, P.J., Shachar-Hill, Y., 2005. Nitrogen transfer in the arbuscular mycorrhizal symbiosis. Nature 435, 819-823.

Holland, S.L., Avery, S.V., 2011. Chromate toxicity and the role of sulfur. Metallomics 3, 1119-1123.

Jiang, Y, Wang, W, Xie, QLiu, N., Liu, L., Wang, D., Zhang, X., Yang, C., Chen, X., Tang, D., Wang, E., 2017. Plants transfer lipids to sustain colonization by mutualistic mycorrhizal and parasitic fungi. Science: 356, 1172-1175.

Johansson, J.F., Paul, L.R., Finlay, R.D., 2004. Microbial interactions in the mycorrhizosphere and their significance for sustainable agriculture. FEMS Microbiology Ecology 48, 1-13.

Karandashov, V., Bucher, M., 2005. Symbiotic phosphate transport in arbuscular mycorrhizas. Trends in Plant Science 10, 22-29.

Khan, A.G., 2001. Relationships between chromium biomagnification ratio, accumulation factor, and mycorrhizae in plants growing on tannery effluent-polluted soil. Environment International 26, 417423. 
Kováčik, J., Babula, P., Klejdus, B., Hedbavny, J., 2013. Chromium uptake and consequences for metabolism and oxidative stress in chamomile plants. Journal of Agricultural and Food Chemistry 61, 7864-7873.

Kuga, Y., Saito, K., Nayuki, K., Peterson, R.L., Saito, M., 2008. Ultrastructure of rapidly frozen and freeze-substituted germ tubes of an arbuscular mycorrhizal fungus and localization of polyphosphate. New Phytologist 178, 189-200.

Lenoir, I., Fontaine, J., Lounès-Hadj Sahraoui, A., 2016. Arbuscular mycorrhizal fungal responses to abiotic stresses: A review. Phytochemistry 123, 4-15.

Leyval, C., Singh, B.R., Joner, E.J., 1995. Occurrence and infectivity of arbuscular mycorrhizal fungi in some Norwegian soils influenced by heavy metals and soil properties. Water, Air, and Soil Pollution 84, 203-216.

Leyval, C., Turnau, K., Haselwandter, K., 1997. Effect of heavy metal pollution on mycorrhizal colonization and function: physiological, ecological and applied aspects. Mycorrhiza 7, 139-153.

Long, L.K., Yao, Q., Guo, J., Yang, R.H., Huang, Y.H., Zhu, H.H., 2010. Molecular community analysis of arbuscular mycorrhizal fungi associated with five selected plant species from heavy metal polluted soils. European Journal of Soil Biology 46, 288-294.

Losi, M., Amrhein, C., Frankenberger, W. Jr, (1994) Environmental biochemistry of chromium. In: Ware GW (ed) Reviews of Environmental Contamination and Toxicology, Springer, New York, NY, USA, pp 91-121.

Ma, Y., Dickinson, N.M., Wong, M.H., 2006. Beneficial effects of earthworms and arbuscular mycorrhizal fungi on establishment of leguminous trees on $\mathrm{Pb} / \mathrm{Zn}$ mine tailings. Soil Biology \& Biochemistry 38, 1403-1412.

Malcová, R., Vosátka, M., Gryndler, M., 2003. Effects of inoculation with Glomus intraradices on lead uptake by Zea mays L. and Agrostis capillaris L. Applied Soil Ecology 23, 55-67.

Miransari, M., 2011. Interactions between arbuscular mycorrhizal fungi and soil bacteria. Applied Microbiology and Biotechnology 89, 917-930.

Nakatani, A.S., Mescolotti, D.L.C., Nogueira, M.A., Martines, A.M., Miyauchi, M.Y.H., Stürmer, S.L., Cardoso, E.J.B.N., 2011. Dosagedependent shift in the spore community of arbuscular mycorrhizal fungi following application of tannery sludge. Mycorrhiza 21, 515 522.

Nayuki, K., Chen, B., Ohtomo, R., Kuga, Y., 2014. Cellular imaging of cadmium in resin sections of arbuscular mycorrhizas using synchrotron micro X-ray fluorescence. Microbes and Environments 29, 60-66.

Nichols, K., 2003. Characterization of glomalinda glycoprotein produced by arbuscular mycorrhizal fungi. PhD Dissertation, University of Maryland, College Park, Maryland.

Orłowska, E., Przybyłowicz, W., Orlowski, D., Turnau, K., MesjaszPrzybyłowicz, J., 2011. The effect of mycorrhiza on the growth and elemental composition of Ni-hyperaccumulating plant Berkheya coddii Roessler. Environmental Pollution 159, 3730-3738.

Pereira, Y., Lagniel, G., Godat, E., Baudouin-Cornu, P., Junot, C., Labarre, J., 2008. Chromate causes sulfur starvation in yeast. Toxicological Sciences 106, 400-412.

Rahmaty, R., Khara, J., 2011. Effects of vesicular arbuscular mycorrhiza Glomus intraradices on photosynthetic pigments, antioxidant enzymes, lipid peroxidation, and chromium accumulation in maize plants treated with chromium. Turkish Journal of Biology 35, 51-58.

Repetto, O., Bestel-Corre, G., Dumas-Gaudot, E., Berta, G., Gianinazzi-Pearson, V., Gianinazzi, S., 2003. Targeted proteomics to identify cadmium-induced protein modifications in Glomus mosseae-inoculated pea roots. New Phytologist 157, 555-567.

Rufyikiri, G., Thiry, Y., Declerck, S., 2003. Contribution of hyphae and roots to uranium uptake and translocation by arbuscular mycorrhizal carrot roots under root-organ culture conditions. New Phytologist 158, 391-399.

Shanker, A.K., Cervantes, C., Loza-Tavera, H., Avudainayagam, S., 2005. Chromium toxicity in plants. Environment International 31 , 739-753.

Shanker, A.K., Pathmanabhan, G., 2004. Speciation dependant antioxidative response in roots and leaves of sorghum (Sorghum bicolor (L.) Moench cv CO 27) under $\mathrm{Cr}(\mathrm{III})$ and $\mathrm{Cr}$ (VI) stress. Plant and Soil 265, 141-151.

Sharma, D.C., Sharma, C.P., Tripathi, R.D., 2003. Phytotoxic lesions of chromium in maize. Chemosphere 51, 63-68.

Singh, J., Kumar, M., Vyas, A., 2014. Healthy response from chromium survived pteridophytic plant-Ampelopteris prolifera with the interaction of mycorrhizal fungus-Glomus deserticola. International Journal of Phytoremediation 16, 524-535.

Singh, S., Parihar, P., Singh, R., Prasad, S.M., 2015. Heavy metal tolerance in plants: role of transcriptomics, proteomics, metabolomics, and ionomics. Frontiers of Plant Science, 6, 1143.

Skeffington, R.A., Shewry, P.R., Peterson, P.J., 1976. Chromium uptake and transport in barley seedlings (Hordeum vulgare L.). Planta 132, 209-214.

Smith, S.E., Read, D., (2008) Mycorrhizal Symbiosis. Academic Press, San Diego.

Subramanian, K.S., Tenshia, V., Jayalakshmi, K., Ramachandran, V., 2009. Biochemical changes and zinc fractions in arbuscular mycorrhizal fungus (Glomus intraradices) inoculated and uninoculated soils under differential zinc fertilization. Applied Soil Ecology 43, 32-39.

Sun, Y., Zhang, X., Wu, Z., Hu, Y., Wu, S., Chen, B., 2016. The molecular diversity of arbuscular mycorrhizal fungi in the arsenic mining impacted sites in Hunan Province of China. Journal of Environmental Sciences (China) 39, 110-118.

Vodnik, D., Grcman, H., Macek, I., van Elteren, J.T., Kovacevic, M., 2008. The contribution of glomalin-related soil protein to $\mathrm{Pb}$ and $\mathrm{Zn}$ sequestration in polluted soil. Science of the Total Environment 392, 130-136.

Wang, F., 2017. Occurrence of arbuscular mycorrhizal fungi in miningimpacted sites and their contribution to ecological restoration: Mechanisms and applications. Critical Reviews in Environmental Science and Technology 47, 1901-1957.

Weiersbye, I.M., Straker, C.J., Przybylowicz, W.J., 1999. Micro-PIXE mapping of elemental distribution in arbuscular mycorrhizal roots of the grass, Cynodon dactylon, from gold and uranium mine tailings. Nuclear Instruments and Methods in Physics Research Section B 158, 335-343.

Weissenhorn, I., Leyval, C., Berthelin, J., 1995. Bioavailability of 
heavy metals and abundance of arbuscular mycorrhiza in a soil polluted by atmospheric deposition from a smelter. Biology and Fertility of Soils 19, 22-28.

Wu, S., Vosátka, M., Vogel-Mikus, K., Kavčič, A., Kelemen, M., Šepec, L., Pelicon, P., Skála, R., Valero Powter, A.R., Teodoro, M., Michálková, Z., Komárek, M., 2018b. Nano zero-valent iron mediated metal (loid) uptake and translocation by arbuscular mycorrhizal symbioses. Environmental Science \& Technology 52 , 7640-7651.

Wu, S., Zhang, X., Sun, Y., Wu, Z., Li, T., Hu, Y., Lv, J., Li, G., Zhang, Z., Zhang, J., Zheng, L., Zhen, X., Chen, B., 2016b. Chromium immobilization by extra-and intraradical fungal structures of arbuscular mycorrhizal symbioses. Journal of Hazardous Materials $316,34-42$.

Wu, S., Zhang, X., Sun, Y., Wu, Z., Li, T., Hu, Y., Su, D., Lv, J., Li, G., Zhang, Z., Zheng, L., Zhang, J., Chen, B., 2015. Transformation and immobilization of chromium by arbuscular mycorrhizal fungi as revealed by SEM-EDS, TEM-EDS, and XAFS. Environmental Science \& Technology 49, 14036-14047.

Wu, S.L., Chen, B.D., Sun, Y.Q., Ren, B.H., Zhang, X., Wang, Y.S., 2014. Chromium resistance of dandelion (Taraxacum platypecidum Diels.) and bermudagrass (Cynodon dactylon [Linn.] Pers.) is enhanced by arbuscular mycorrhiza in $\mathrm{Cr}(\mathrm{VI})$-contaminated soils. Environmental Toxicology and Chemistry 33, 2105-2113.

Wu, S.L., Hu, Y.J., Zhang, X., Sun, Y., Wu, Z., Li, T., Lv, J., Li, J., Zhang, J., Zheng, L., Huang, L., Chen, B., 2018a. Chromium detoxification in arbuscular mycorrhizal symbiosis mediated by sulfur uptake and metabolism. Environmental and Experimental Botany $147,43-52$.

Wu, S.L., Zhang, X., Chen, B.D., 2013. Effects of Arbuscular mycorrhizal fungi on heavy metal translocation and transformation in the soil-plant continuum. Asian Journal of Ecotoxicology 8, 847856 (in Chinese).

Wu, S.L., Zhang, X., Chen, B.D., Wu, Z., Li, T., Hu, Y., Sun, Y., Wang, Y., 2016a. Chromium immobilization by extraradical mycelium of arbuscular mycorrhiza contributes to plant chromium tolerance.
Environmental and Experimental Botany 122, 10-18.

Yang, Y., Han, X., Liang, Y., Ghosh, A., Chen, J., Tang, M., 2015. The combined effects of arbuscular mycorrhizal fungi (AMF) and lead $(\mathrm{Pb})$ stress on $\mathrm{Pb}$ accumulation, plant growth parameters, photosynthesis, and antioxidant enzymes in Robinia pseudoacacia L. PLoS One 10, e0145726.

Yu, Y., Zhang, S., Huang, H., Luo, L., Wen, B., 2009. Arsenic accumulation and speciation in maize as affected by inoculation with arbuscular mycorrhizal fungus Glomus mosseae. Journal of Agricultural and Food Chemistry 57, 3695-3701.

Yu, Y., Zhang, S.Z., Huang, H.L., Wu, N., 2010. Uptake of arsenic by maize inoculated with three different arbuscular mycorrhizal fungi. Communications in Soil Science and Plant Analysis 41, 735-743.

Yu, Y.G., Zhao, B., 2008. The interaction and effect of two species of arbuscular mycorrhizal fungi on the growth of Astragalus sinicus $\mathrm{L}$ at different pH level. Mycosystema 27, 209-216 (in Chinese).

Zarei, M., Hempel, S., Wubet, T., Schäfer, T., Savaghebi, G., Jouzani, G.S., Nekouei, M.K., Buscot, F., 2010. Molecular diversity of arbuscular mycorrhizal fungi in relation to soil chemical properties and heavy metal contamination. Environmental Pollution 158, 2757-2765

Zayed, A., Lytle, C.M., Qian, J.H., Terry, N., 1998. Chromium accumulation, translocation and chemical speciation in vegetable crops. Planta 206, 293-299.

Zhang, S., Feng, G., Li, X., 2005. The direct effect of cadmium in soil on growth of arbuscular mycorrhizal fungi Glomus mosseae. Mycosystema 24, 576-581 (in Chinese).

Zhang, X., Ren, B.H., Wu, S.L., Sun, Y.Q., Lin, G., Chen, B.D., 2015. Arbuscular mycorrhizal symbiosis influences arsenic accumulation and speciation in Medicago truncatula L. in arsenic-contaminated soil. Chemosphere 119, 224-230.

Zhang, X.H., Lin, A.J., Zhang, X., Guo, L.P. 2012. The effects of arbuscular mycorrhizal fungi (AMF) on forms of $\mathrm{Pb}$ in the upland rice rhizosphere. Chinese Agricultural Science Bulletin 28, 24-29 (in Chinese). 